\title{
Identifying Barriers to Mental Health Help-Seeking in French University Students during the Covid-19 Pandemic
}

\author{
Anne Theurel ${ }^{1,2}$, Arnaud Witt ${ }^{2}$ \\ ${ }^{1}$ Instance Régionale d'éducation et de promotion de la santé, Dijon, France \\ ${ }^{2}$ LEAD-CNRS (UMR 5022), Université Bourgogne Franche-Comté, Dijon, France \\ Email: a.theurel@ireps-bfc.org, arnaud.witt@u-bourgogne.fr
}

How to cite this paper: Theurel, A., \& Witt, A. (2022). Identifying Barriers to Mental Health Help-Seeking in French University Students during the Covid-19 Pandemic. Creative Education, 13, 437-449. https://doi.org/10.4236/ce.2022.132025

Received: December 31, 2021

Accepted: February 11, 2022

Published: February 14, 2022

Copyright $\odot 2022$ by author(s) and Scientific Research Publishing Inc. This work is licensed under the Creative Commons Attribution International License (CC BY 4.0).

http://creativecommons.org/licenses/by/4.0/ (c) (i) Open Access

\begin{abstract}
The Covid-19 pandemic has dramatically impacted university student's mental health, a population already known to be vulnerable for developing mental disorders and to demonstrate poor help-seeking behaviours for their mental health. Identifying why university students may choose not to seek help event if needed is an important step towards facilitating early access to mental health services and improving psychological wellbeing. This study aims to investigate help-seeking behaviour and barriers to help-seeking in university students. In December 2020, 182 students from a French university in Bourgogne Franche-Comté participated in an online survey that measured help-seeking behaviours and barriers to accessing mental help. Results showed that $63 \%$ of participants reported they would not seek any formal or informal help if dealing with an emotional or mental health difficulty. Most of students reported a preference toward informal help from friends and family compared to help form professionals. Seeking mental health-related information and support on the internet was also a relatively common behaviour. University students perceive a number of barriers to help-seeking for mental health problems. These include a preference for self-reliance, poor emotional competence and mental health literacy, and cost and time constraints. We discussed how the results of the present survey provide crucial information for policymakers to adopt strategies for improving help-seeking by university students.
\end{abstract}

\section{Keywords}

Help-Seeking Behaviour, Barriers to Help-Seeking, Mental Health, Attitudinal Barriers, University Students 


\section{Introduction}

Following the Covid-19 pandemic, the French population has been successively put into lockdown from 17 March 2020 for almost two months and from 30 October 2020 for one month and a half. After the first announcement of universities closure on March 2020, the latter finally remained closed for almost 1 year. Available evidence showed elevated psychiatric symptoms among university students during successive lockdown and suggested an unprecedented impact of the pandemic on the mental health of university students (Arsandaux et al., 2020; Kecojevic et al., 2020; Roux et al., 2021; Sun et al., 2021; Wathelet et al. 2020). In France, findings show that students suffer from particularly high level of anxiety, depression and distress and suggest that the epidemic and confinement have increased the emergence of post-traumatic stress symptoms (Essadek \& Rabeyron, 2020). Indeed, the Covid-19 pandemic has led to massive disruption in the lives and education of university students, through prolonged university closure, subsequent shift to an emergency online learning format, and the reduction or elimination of social contacts and cultural activities, that have affected disproportionally students' mental health (Kohls et al., 2021). In addition, the abrupt closure of campus has led to loss of daily routines and may have exacerbate academic stressors for students with increased pressures to learn independently and higher rates of dropout (Grubic et al., 2020).

Even before the pandemic, university students were considered as particularly vulnerable to mental health disorders, with one third of students experiencing significant mental health problems ranging from depression and anxiety to suicidality (Eisenberg et al., 2013). Stressors such as demanding coursework, time pressure, poor interpersonal relationships with peers/teachers (Basson \& Rothmann, 2019; Bewick et al., 2010; Mertens et al., 2020), social isolation, peer pressure, and study-life imbalances (Bergin \& Pakenham, 2015) can promote the occurrence of a mental illness in university students. Furthermore, studies have shown that students struggle to cope with these stressors and do not possess the necessary personal resources to buffer against the effects thereof on their mental health (Mokgele \& Rothmann, 2014). These stressors not only affect students' day-to-day activities but also have negative consequences on physical and mental health (Martineau, Beauchamp, \& Marcotte, 2017), as well as cause considerable long-term health and adjustment problems (Rickwood et al., 2005).

Thus, the Covid-19 pandemic increased stressors in a population with pre-existing elevated stress levels and a reduced ability to rely on effective coping strategies, leading to an unprecedented mental health burden on university students.

The high prevalence of mental health problems among young adults and university students is coupled with a strong reluctance to seek professional help (Rickwood et al., 2007). Many students do not have access or choose not to seek help from healthcare services even when they need mental healthcare (Cheung \& Dewa, 2007; Pottick et al., 2008). In France, more than one in five students with 
a mental health problem report not seeking help (Morvan et al., 2016). For example, a French survey (OVE, 2016) showed that among the 15\% of students who suffered from depression, only 53\% sought mental health care. A French study (Verger et al., 2010) showed that only $30.5 \%$ of students presenting one or more signs of psychological distress in the past year sought care from a health professional. Thus, a significant proportion of students suffering from psychological distress do not seek care from professionals. Help-seeking even decreased during the lockdown, with only $12 \%$ of students with at least 1 outcome reported seeing a mental health professional, and 3\% using the university service (Wathelet et al., 2020), during the $1^{\text {st }}$ lockdown.

Since the Covid-19 pandemic, improving students' wellbeing and access to mental health services has become a key agenda in government policies. Limited available provision, long waiting lists and cost of specialist services were key barriers identified by the French government for accessing mental health services. This has prompted a range of recent initiatives designed to increase the availability and accessibility of specialist services (e.g. "chèque psy", reimbursement of consultations with psychologists, etc.) and reduce the pressure on health systems to manageable levels (Lafon, 2021).

Despite a conscious move towards structural barriers for improving students access to mental health care, evidence suggests that individual factors, such as personal beliefs, internalised gender norms, coping skills, self-efficacy, and perceived stigma play a major role in explaining help-seeking behaviours and interact with structural factors such as accessibility and affordability of services (Barker et al., 2005). Indeed, personal determinants such as personal preferences for self-reliance in managing their mental health, negative attitudes about seeking professional help, a preference for informal sources of help, are major barriers to help-seeking in young people (Gulliver et al., 2010; Radez et al., 2021; Salaheddin, \& Mason, 2016). Although existing studies have focused on mental health help-seeking among adolescents (Gulliver et al., 2010; Radez et al., 2021; Rickwood et al., 2005), young adults (Gulliver et al., 2010; Salaheddin \& Mason 2016) or adults of all ages (Clement et al., 2015), few have reported on the barriers experienced by university students and no one during the Covid-19 pandemic in France. It is critical that efforts to improve access to support and services take into account students' views on help-seeking, and by doing so address the barriers that impede seeking help from professionals. A detailed understanding of the reasons that university students (rather than professionals or government) do not seek, and access professional help is crucial to address the gap between the high prevalence of mental health disorders in this population and low treatments utilisation.

The aim of this study was to explore help-seeking behaviours and barriers to seeking mental help support in young adults aged 18 - 27 years studying in a French university during the Covid-19 pandemic. 


\section{Methods}

\subsection{Participants and Procedure}

Given the scenario of social distancing of COVID-19 pandemic, it was necessary to use digital research tools. In November 2020, we carried out a focus group to explore help-seeking with 4 volunteers (aged 20 - 25 years) from students' organisations, using Zoom videoconferencing platform. The findings were used to inform the content of the questionnaires developed to measure help-seeking behaviours and perceived barriers to seeking help.

An online survey was then developed with the SurveyMonkey software, a professional tool that allows to create multiple choices or scale-format questionnaires. Data collection took place from $12 / 07 / 2020$ to $12 / 18 / 2020$ during the $2^{\text {nd }}$ lockdown in France.

All registered students at the university were invited to participate in the study via an email web-link. The first page of the survey provided study information, assuring volunteers that participation was voluntary and anonymous. Exclusion criteria were that participants had to be a current student and over the age of 18 , which eliminated 15 respondents. The final sample consisted of 182 students who completed all elements of the survey. Participant ages ranged from 18 to 27 $(M=20.47, S D=2.17)$.

\subsection{Measurement}

The survey consisted of an online questionnaire that measured help-seeking behaviour and barriers to seeking help Help-seeking behaviours were assessed by asking participants how they seek help when dealing with emotional or psychological issues. Participants were presented with the following multi-choice answers: "I talk to a friend about it", "I talk to someone in my family about it", "I talk to my GP about it", "I seek help from a mental health professional (psychologist/psychiatrist)", "I use a phone counselling service (e.g. Fil santé jeunes)", "I am looking for information that can help me on the internet", "I'm waiting the problem would get better by itself".

All participants were then presented with an adapted version of the 30-item Barriers to Access to Care Evaluation (BACE) scale, (Clement et al., 2012) to assess barriers to seeking professional help by asking participants if any of the following issues ever stopped, delayed or discouraged them from getting professional help for a mental health problem. This adapted version of the BACE consists of a 16-items scale assessing stigma-related, attitudinal and instrumental barrier on a 5-point Likert scale.

\subsection{Data Analysis}

We analyzed the participants' answers from the Excel data automatically generated in the Survey Monkey platform. The percentage of participants who selected each answer was calculated and quantitative analysis and descriptive statistics were performed. 


\section{Results}

\subsection{Students' Help-Seeking Behaviours}

The percentage of all participants reporting each help-seeking behaviour is presented in Table 1.

Table 1. Percentage of students reporting each help-seeking behaviour.

\begin{tabular}{lc}
\hline \multicolumn{1}{c}{ Help-seeking behaviours } & $\%(\mathrm{n})$ \\
\hline I talk to a friend about it & $55.49(101)$ \\
I talk to someone in my family about it & $36.26(66)$ \\
I talk to my GP about it & $1.65(3)$ \\
I seek help from a mental health professional (psychologist/psychiatrist) & $6.59(12)$ \\
I call a hotline (e.g. Fil santé jeunes) & $0(0)$ \\
I am looking for information that can help me on the internet & $18.68(34)$ \\
I'm waiting the problem would get better by itself & $63.19(115)$ \\
\hline
\end{tabular}

When dealing with emotional or psychological issues, most of the students (63\%) are waiting the problem would get better by itself. They then prefer to ask for help from their friends (55\%) or a family member (36\%). About 1 in 5 students (19\%) is seeking advice on the Internet. Searching for professional help is less common among students with only $7 \%$ of students that reported seeking help from a mental health professional (psychologist/psychiatrist) $2 \%$ from their general practitioner. No students used hotline to seek help.

\subsection{Perceived Barriers for Help-Seeking}

The percentage of all participants reporting the degree to which each barrier item would "stop, delay, or discourage" them from seeking professional help is presented in Table 2. Each barrier was ranked according to the items being rated as a "major barrier".

All barriers confounded, the five major barriers to help-seeking being reported by participants are in rank order: "wanting to solve the problem on my own" (51.10\%), "dislike of talking about my feelings, emotions, or thoughts" (50\%), "not being able to afford the financial costs" (46.7\%), "difficulty to find time with my other duties" (34.07\%) and, ex-aequo, "unsure where to get professional care" and "preferring to get help from family or friends" with $28.02 \%$.

The most highly-rated stigma barrier was "Concern about what my friends might think, say, or do", with $26.37 \%(\mathrm{n}=48)$ of participants anticipating that this would prevent or delay them from seeking professional help. The most commonly-anticipated attitudinal barrier was "Wanting to solve the problem on my own, whereby $96.15 \%(n=175)$ of participants reported that this would be a barrier to some degree and with $51.10 \%(n=93)$ of participants reported that it would act as a major barrier to them seeking professional help if needed. The 
Table 2. Percentage, frequencies, and mean scores of the BACE.

\section{Barrier items}

\begin{tabular}{|c|c|c|}
\hline $\begin{array}{l}\text { Reporting item } \\
\text { as not at all } \\
\text { a barrier \% (n) }\end{array}$ & $\begin{array}{l}\text { Reporting item } \\
\text { as a barrier to } \\
\text { any degree \% (n) }\end{array}$ & $\begin{array}{l}\text { Reporting item } \\
\text { as a major } \\
\text { barrier \% (n) }\end{array}$ \\
\hline
\end{tabular}

\section{Stigma-related barrier items}

Concern about what my friends might think, say, or do

$\begin{array}{llll}24.73(45) & 75.27(137) & 26.37(48) & 2.16(1.72) \\ 24.73(45) & 75.27(137) & 26.37(48) & 2.11(1.68) \\ 29.12(53) & 70.88(129) & 24.18(44) & 1.98(1.74) \\ 29.12(53) & 70.88(129) & 24.18(44) & 1.94(1.71) \\ 25.27(46) & 74.73(136) & 21.98(40) & 2.16(1.67)\end{array}$

Concern about what my family might think, say, or do

Concern that I might be seen as weak for having a mental

health problem

Concern that I might be seen as "crazy"

Feeing embarrassed or ashamed

$3.85(7)$

96.15 (175)

$51.10(93)$

$3.34(1.41)$

Dislike of talking about my feelings, emotions, or thoughts

$8.79(16)$

$91.21(166)$

$50.00(91)$

$3.09(1.71)$

Preferring to get help from family or friends

$18.13(33)$

81.87 (149)

$28.02(51)$

$2.38(1.66)$

Thinking the problem would get better by itself

15.38 (28)

84.62 (154)

23.63 (43)

2.32 (1.53)

Thinking I did not have a problem

$31.32(57)$

68.68 (125)

17.58 (32)

$1.75(1.65)$

Thinking that professional care would not help

$34.62(63)$

65.38 (119)

17.58 (32)

$1.68(1.64)$

\section{Instrumental barrier items}

Not being able to afford the financial costs

\begin{tabular}{llll}
$20.33(37)$ & $79.67(145)$ & $46.70(85)$ & $2.92(1.88)$ \\
$19.78(36)$ & $80.22(146)$ & $34.07(62)$ & $2.54(1.76)$ \\
$24.73(45)$ & $75.27(137)$ & $28.02(51)$ & $2.27(1.75)$ \\
$28.02(51)$ & $71.98(131)$ & $24.18(44)$ & $2.11(1.77)$ \\
$50.00(91)$ & $50.00(91)$ & $12.64(23)$ & $1.30(1.63)$ \\
\hline
\end{tabular}

Difficulty to find time with my other duties

Unsure where to get professional care

Difficulty to get an appointment

Problems with transport/travel to appointments

most commonly-rated instrumental barrier was "not being able to afford the financial costs" involved in seeking professional help, with 46.7\% ( $\mathrm{n}=85$ ) participants reported that it would act as a major barrier to help-seeking.

\section{Discussion}

This study found that, when dealing with emotional or psychological issues, most of the students (63\%) did not seek any formal or informal help but waited the problem would get better by itself. Although this study assessed anticipated help-seeking behaviour and that the prevalence of participants in the sample concerned with a mental health or emotional difficulty was unknown, this finding suggests similar rate of help-seeking than observed in previous French studies in young adults (e.g., Verger et al., 2010).

Results also showed that informal help is preferred by students than formal help. This finding confirmed previous results observed in youngest adolescents, namely that young people are more likely to seek help from their friends and 
family for psychological and emotional problems than from other sources, including mental health professionals (Rickwood et al., 2005).

Searching for professional help is less common among students with only 7\% of students that reported seeking help from a mental health professional (psychologist/psychiatrist) and $2 \%$ from their general practitioner. The present findings add to the existing evidence that, compared with other adults, young people did not value or recognise GPs as a potential source of support for their psychological distress, (e.g., Biddle et al., 2006). In Biddle et al. (2006) study, young adults reported "believing that GPs deal exclusively with physical illness", "lack of training in mental health", "cannot provide talking therapy", and "only prescribing unwanted medication" as major barriers to consult their GP when dealing with psychological problems. Such negative perceptions about GPs as a help resource are at odds with the new key role assigned to GPs in the prescription of mental health services in France. Although government directives are seeing primary care practitioners as the "gatekeepers" to young people's mental health service, evidence reported that GPs also report a number of barriers that compromise their delivery of mental health care, including time constraints and a lack of specific mental health knowledge that leave them feeling poorly equipped to offer alternatives to drug therapy (O'Brien et al., 2016). These findings have practical implications for the training of GPs. There is a need to improve the ability and confidence of GPs to recognise mental health problems in young people and to facilitate help-seeking by providing information about the availability and effectiveness of mental health services.

Results also showed that 1 in 5 students (19\%) use the internet for information and support seeking. These findings are in line with a recent review (Montagni et al., 2020) showing that seeking mental health-related information on the internet was a relatively common behaviour among all students According to this review, most searched topics are depression, stress, anxiety and general information on mental health problems that students themselves or their family or friends experienced.

Regarding on barriers to help-seeking, the results indicate that barriers to accessing mental health in university students mostly result from attitudinal barriers such as a preference for self-reliance, difficulty expressing thoughts and emotions and a preference for friends or family sources of help, as well as instrumental barriers such as cost, time constraints and availability of professional help. Nonetheless, the present findings did not confirm the existing evidence that shame, embarrassment and stigma surrounding mental health is a major barrier to help-seeking (e.g., Clement et al., 2015). However, other studies have found low overall stigma-related attitudes in students and found that perceived barriers to help-seeking differed significantly by age with younger individuals more likely to perceive a significantly greater number of stigma-related barriers than older individuals (Vidourek et al., 2014). Although mental health literacy interventions appear to be more effective in improving help-seeking attitudes in young 
adults (Gulliver et al., 2012), it is to be noted that interventions that use strategies of destigmatisation are effective in terms of improving attitudes to seek formal help (Shahwan et al., 2020; Xu et al., 2018), at least when integrated as a component of the intervention (Griffiths et al., 2017; Johnson et al., 2021).

Although several limitations to the study should be considered when reviewing the results, this study has provided some rich quantitative information that contributes to the understanding of why university students may choose not to seek help for their mental health problems during the Covid-19 pandemic.

Limitations of this study include the use of an online survey for data collection, which excluded any individuals without internet access. The limited sample size may limit the generalisability of the findings to the wider population of university students. A further limitation was imposed by the use of the BACE scale which measure anticipated barriers to help-seeking instead of actual help-seeking behaviours. Thus, no conclusions should be drawn regarding the extent that these barriers would hinder or prevent actual help-seeking behaviour. Finally, barriers and facilitators may vary across the different points of the help-seeking process, as well as vary according to the actual presence of psychological symptoms (Montagni et al., 2020). Future research should investigate more sophistically these factors as they operate at each level of the help-seeking process. Furthermore, qualitative research may have provided additional and different information about the reasons that university students do not seek help to structured survey questions.

\section{Practical Recommendations}

The Covid-19 pandemic and associated governmental restriction measures have led to increases in the prevalence of mental health disorders in university students compared to previous years (Chirikov et al., 2020) and the impact on students' mental health seems to be persistent (Copeland et al., 2021). The findings of the present study suggest a number of ways forward in order to help universities and policymakers to address the continued mental health impacts of the pandemic.

First, findings indicate a need to adopt strategies for improving help-seeking by university students that take into account their desire for self-reliance. A promising approach involves providing them evidence-based self-help material. Digital tools appear as a promising means to increase access to mental health support in young people (Griffiths \& Christensen, 2006). On average, 1 university student out of 10 had accessed at least once a mental health support platform or mobile application for support seeking (Montagni et al., 2016). If e-mental health is considered by students either as an alternative help resource compared with traditional consultations, or as a complementary tool to traditional care that cannot replace face-to-face consultations, all reviewed articles suggested that digital tools are seen as very useful because they can counteract two main barriers: lack of time and fear of being stigmatized through anonymity, privacy and 
confidentiality (Montagni et al., 2020). Given students' high need for online mental health information and their preparedness to use new technologies for psychological support, digital tools have the potential to promote students' psychological well-being and prevent mental health problems. Furthermore, as students reported trusting information provided by official and reliable institutions, including their university (Montagni et al., 2020), health professionals and academic staff should take leadership roles in producing and disseminating e-mental health information within the university setting. There is to be noted that, to encourage and support young adults to seek professional help early for emerging mental health problems, digital services must be informed and guided by the young people themselves (Torous et al., 2018).

In addition, digital tools have also the potential for providing cost-effective mental health interventions via web- or mobile-based platforms, thus addressing the barrier to help and treatment seeking related to financial concerns (e.g., Ebert et al., 2018). Internet-based self-help programs, such as MoodGym, have been shown to be successful at reducing mental health problems such as depression or generalized anxiety (e.g., Christensen et al., 2004). Similarly, internet-based self-help program might be helpful for those who find it hard to talk about their thoughts and feelings in person (Fleming et al., 2012), thus addressing barrier related to difficulty expressing thoughts and emotions. As young adults need to know how to identify, describe, or manage their emotions in an effective and non-defensive manner, in order to seek mental health help (e.g., Ciarrochi et al., 2003), such online self-help program should include emotional competence training.

Finally, the barrier related to a preference for friends or family sources of help suggests that friends and family could therefore have a significant role in the help-seeking process, and more particularly in the pathway to professional services. Developing good mental health literacy in students' key helpers (friends, family, university staff) may lead to better outcomes for those with mental health problems, either by facilitating early help-seeking by students themselves, or by helping their friends and other adults (university staff or family members) to identify early signs of mental health disorders and seek help on their behalf. Mental health literacy comprises the ability to recognise mental health problems, knowledge and beliefs about risks, effective treatments, and knowledge of how to seek mental health information and services (Jorm et al., 1997). In that vein, studies suggested the effectiveness of Mental Health First Aid training in improving mental health literacy and appropriate support for those with mental health problems up to 6 months after training (Morgan et al., 2018). Such intervention should be systematically considered in initiatives to promote students' mental health.

\section{Conflicts of Interest}

The authors declare no conflicts of interest regarding the publication of this paper. 


\section{References}

Arsandaux, J., Montagni, I., Macalli, M., Texier, N., Pouriel, M., Germain, R. et al. (2020). Higher Risk of Mental Health Deterioration during the Covid-19 Lockdown among Students rather than Non-Students. The French Confins Study. medRxiv. https://doi.org/10.1101/2020.11.04.20225706

Barker, G., Olukoya, A., \& Aggleton, P. (2005). Young People, Social Support and Help-Seeking. International Journal of Adolescent Medicine and Health, 17, 315-335. https://doi.org/10.1515/IJAMH.2005.17.4.315

Basson, M. J., \& Rothmann, S. (2019). Pathways to Flourishing among Pharmacy Students: The Role of Study Demands and Lecturer Support. Journal of Psychology in Africa, 29, 338-345. https://doi.org/10.1080/14330237.2019.1647953

Bergin, A., \& Pakenham, K. (2015). Law Student Stress: Relationships between Academic Demands, Social Isolation, Career Pressure, Study/Life Imbalance and Adjustment Outcomes in Law Students. Psychiatry, Psychology and Law, 22, 388-406.

https://doi.org/10.1080/13218719.2014.960026

Bewick, B., Koutsopoulou, G., Miles, J., Slaa, E., \& Barkham, M. (2010). Changes in Undergraduate Students' Psychological Well-Being as They Progress through University. Studies in Higher Education, 35, 633-645. https://doi.org/10.1080/03075070903216643

Biddle, L., Donovan, J. L., Gunnell, D., \& Sharp, D. (2006). Young Adults' Perceptions of GPs as a Help Source for Mental Distress: A Qualitative Study. British Journal of General Practice, 56, 924-931. https://www.ncbi.nlm.nih.gov/pmc/articles/PMC1934052/

Cheung, A. H., \& Dewa, C. S. (2007). Mental Health Service Use among Adolescents and Young Adults with Major Depressive Disorder and Suicidality. The Canadian Journal of Psychiatry, 52, 228-232. https://doi.org/10.1177/070674370705200404

Chirikov, I., Soria, K. M., Horgos, B., \& Jones-White, D. (2020). Undergraduate and Graduate Students' Mental Health during the COVID-19 Pandemic. UC Berkeley: Center for Studies in Higher Education. https://escholarship.org/uc/item/80k5d5hw

Christensen, H., Griffiths, K. M., \& Jorm, A. F. (2004). Delivering Interventions for Depression by Using the Internet: Randomised Controlled Trial. British Medical Journal, 328, Article No. 265. https://doi.org/10.1136/bmj.37945.566632.EE

Ciarrochi, J., Wilson, C. J., Deane, F. P., \& Rickwood, D. (2003). Do Difficulties with Emotions Inhibit Help-Seeking in Adolescence? The Role of Age and Emotional Competence in Predicting Help-Seeking Intentions. Counselling Psychology Quarterly, 16, 103-120. https://doi.org/10.1080/0951507031000152632

Clement, S., Brohan, E., Jeffery, D., Henderson, C., Hatch, S. L., \& Thornicroft, G. (2012). Development and Psychometric Properties the Barriers to Access to Care Evaluation Scale (BACE) Related to People with Mental Ill Health. BMC Psychiatry, 12, Article No. 36. https://doi.org/10.1186/1471-244X-12-36

Clement, S., Schauman, O., Graham, T., Maggioni, F., Evans-Lacko, S., Bezborodovs, N. et al. (2015). What Is the Impact of Mental Health-Related Stigma on Help-Seeking? A Systematic Review of Quantitative and Qualitative Studies. Psychological Medicine, 45, 11-27. https://doi.org/doi:10.1017/S0033291714000129

Copeland, W. E., McGinnis, E., Bai, Y., Adams, Z., Nardone, H., Devadanam, V. et al. (2021). Impact of COVID-19 Pandemic on College Student Mental Health and Wellness. Journal of the American Academy of Child \& Adolescent Psychiatry, 60, 134-141.E2.

Ebert, D. D., Van Daele, T., Nordgreen, T., Karekla, M., Compare, A. T., Zarbo, C. et al. (2018). Internet- and Mobile-Based Psychological Interventions: Applications, Efficacy, and Potential for Improving Mental Health. European Psychologist, 23, 167-187. 
https://doi.org/10.1027/1016 - 9040/a000318

Eisenberg, D., Hunt, J., \& Speer, N. (2013). Mental Health in American Colleges and Universities: Variation across Student Subgroups and across Campuses. The Journal of Nervous and Mental Disease, 201, 60-67. https://doi.org/10.1097/NMD.0b013e31827ab077

Essadek, A., \& Rabeyron, T. (2020). Mental Health of French Students during the Covid-19 Pandemic. Journal of Affective Disorders, 277, 392-393. https://doi.org/10.1016/j.jad.2020.08.042

Fleming, T. M., Dixon, R. S., \& Merry, S. N. (2012). 'It's Mean!' The Views of Young People Alienated from Mainstream Education on Depression, Help Seeking and Computerised Therapy. Advances in Mental Health, 10, 195-203.

https://doi.org/10.5172/jamh.2011.10.2.195

Griffiths, K. M., \& Christensen, H. (2006). Review of Randomised Controlled Trials of Internet Interventions for Mental Disorders and Related Conditions. Clinical Psychologist, 10, 16-29. https://doi.org/10.1080/13284200500378696

Griffiths, K. M., Walker, J., \& Batterham, P. J. (2017). Help Seeking for Social Anxiety: A Pilot Randomised Controlled Trial. Digital Health, 3, 1-12. https://doi.org/10.1177/2055207617712047

Grubic, N., Badovinac, S., \& Johri, A. M. (2020). Student Mental Health in the Midst of the COVID-19 Pandemic: A Call for Further Research and Immediate Solutions. International Journal of Social Psychiatry, 66, 517-518. https://doi.org/10.1177/0020764020925108

Gulliver, A., Griffiths, K. M., \& Christensen, H. (2010). Perceived Barriers and Facilitators to Mental Health Help-Seeking in Young People: A Systematic Review. BMC Psychiatry, 10, Article No. 113. https://doi.org/10.1186/1471-244X-10-113

Gulliver, A., Griffiths, K. M., Christensen, H., \& Brewer, J. L. (2012). A Systematic Review of Help-Seeking Interventions for Depression, Anxiety and General Psychological Distress. BMC Psychiatry, 12, Article No. 81. https://doi.org/10.1186/1471-244X-12-81

Johnson, J. A., Sanghvi, P., \& Mehrotra, S. (2021). Technology-Based Interventions to Improve Help-Seeking for Mental Health Concerns: A Systematic Review. Indian Journal of Psychological Medicine, 1-9. https://doi.org/10.1177/02537176211034578

Jorm, A. F., Korten, A. E., Jacomb, P. A., Christensen, H., Rodgers, B., \& Pollitt, P. (1997). "Mental Health Literacy": A Survey of the Public's Ability to Recognise Mental Disorders and Their Beliefs about the Effectiveness of Treatment. Medical Journal of Australia, 166, 182-186. https://doi.org/10.5694/j.1326-5377.1997.tb140071.x

Kecojevic, A., Basch, C. H., Sullivan, M., \& Davi, N. K. (2020). The Impact of the COVID-19 Epidemic on Mental Health of Undergraduate Students in New Jersey, Cross-Sectional Study. PLOS ONE, 15, e0239696.

https://doi.org/10.1371/journal.pone.0239696

Kohls, E., Baldofski, S., Moeller, R., Klemm, S. L., \& Rummel-Kluge, C. (2021). Mental Health, Social and Emotional Well-Being, and Perceived Burdens of University Students during COVID-19 Pandemic Lockdown in Germany. Frontiers in Psychiatry, 12, Article ID: 643957. https://doi.org/10.3389/fpsyt.2021.643957

Lafon, L. (2021). Rapport d'information fait au nom de la mission d'information sur les conditions de la vie étudiante en France sur l'accompagnement des étudiants: une priorité et un enjeu d'avenir pour l'État et les collectivités. Paris: Sénat, 283 p. http://www.senat.fr/rap/r20-742/r20-7421.pdf

Martineau, M., Beauchamp, G., \& Marcotte, D. (2017). Efficacité des interventions en prévention et en promotion de la santé mentale dans les établissements d'enseignement 
postsecondaire. Santé Mentale au Québec, 42, 165-182.

https://doi.org/10.7202/1040249ar

Mertens, G., Gerritsen, L., Duijndam, S., Salemink, E., \& Engelhard, I. M. (2020). Fear of the Coronavirus (COVID-19): Predictors in an Online Study Conducted in March 2020. Journal of Anxiety Disorders, 74, Article ID: 102258.

https://doi.org/10.1016/j.janxdis.2020.102258

Mokgele, K. R., \& Rothmann, S. (2014). A Structural Model of Student Well-Being. South African Journal of Psychology, 44, 514-527. https://doi.org/10.1177/0081246314541589

Montagni, I., Donisi, V., Tedeschi, F., Parizot, I., Motrico, E., \& Horgan, A. (2016). Internet Use for Mental Health Information and Support among European University Students: The e-MentH Project. Digital Health, 2, 1-16. https://doi.org/10.1177/2055207616653845

Montagni, I., Tzourio, C., Cousin, T., Sagara, J. A., Bada-Alonzi, J., \& Horgan, A. (2020). Mental Health-Related Digital Use by University Students: A Systematic Review. Telemedicine and e-Health, 26, 131-146. https://doi.org/10.1089/tmj.2018.0316

Morgan, A. J., Ross, A., \& Reavley, N. J. (2018). Systematic Review and Meta-Analysis of Mental Health First Aid Training: Effects on Knowledge, Stigma, and Helping Behaviour. PLoS ONE, 13, e0197102. https://doi.org/10.1371/journal.pone.0197102

Morvan, Y., Coulange, I., Krebs, M. O., Boujut, E., \& Romo, L. (2016). La santé psychique des étudiants. In: Giret, J.F., Van de Velde, C. and Verley, É., Eds., Les vies étudiantes. Tendances et inégalités (pp. 213-234) Paris: La documentation Française. https://hal.archives-ouvertes.fr/hal-01550728

O’Brien, D., Harvey, K., Howse, J., Reardon, T., \& Creswell, C. (2016). Barriers to Managing Child and Adolescent Mental Health Problems: A Systematic Review of Primary Care Practitioners' Perceptions. British Journal of General Practice, 66, e693-e707. https://doi.org/10.3399/bjgp16X687061

OVE-Observatoire de la vie étudiante (2016). Enquête nationale Conditions de vie des étudiants en France 2016. Observatoire de la Vie Etudiante. http://www.ove-national.education.fr/enquete/enquete-conditions-de-vie/

Pottick, K. J., Bilder, S., Vander Stoep, A., Warner, L. A., \& Alvarez, M. F. (2008). US Patterns of Mental Health Service Utilization for Transition-Age Youth and Young Adults. The Journal of Behavioral Health Services \& Research, 35, 373-389. https://doi.org/10.1007/s11414-007-9080-4

Radez, J., Reardon, T., Creswell, C., Lawrence, P. J., Evdoka-Burton, G., \& Waite, P. (2021). Why Do Children and Adolescents (Not) Seek and Access Professional Help for Their Mental Health Problems? A Systematic Review of Quantitative and Qualitative Studies. European Child \& Adolescent Psychiatry, 30, 183-211. https://doi.org/10.1007/s00787-019-01469-4

Rickwood, D. J., Deane, F. P., \& Wilson, C. J. (2007). When and How Do Young people Seek Professional Help for Mental Health Problems? Medical Journal of Australia, 187, S35-S39. https://www.mja.com.au/system/files/issues/187 $07011007 /$ ric10279 fm.pdf

Rickwood, D., Deane, F. P., Wilson, C. J., \& Ciarrochi, J. (2005). Young People's Help-Seeking for Mental Health Problems. Australian e-Journal for the Advancement of Mental Health, 4, 218-251. https://ro.uow.edu.au/hbspapers/2106/

Roux, J., Lefort, M., Bertin, M., Padilla, C., Mueller, J., Garlantézec, R. et al. (2021). Impact de la crise sanitaire de la COVID-19 sur la santé mentale des étudiants à Rennes, France. https://hal.archives-ouvertes.fr/hal-03172226

Salaheddin, K., \& Mason, B. (2016). Identifying Barriers to Mental Health Help-Seeking 
among Young Adults in the UK: A Cross-Sectional Survey. British Journal of General Practice, 66, e686-e692. https://doi.org/10.3399/bjgp16X687313

Shahwan, S., Lau, J. H., Goh, C. M. J., Ong, W. J., Tan, G. T. H., Kwok, K. W. et al. (2020). The Potential Impact of an Anti-Stigma Intervention on Mental Health Help-Seeking Attitudes among University Students. BMC Psychiatry, 20, Article No. 562.

https://doi.org/10.1186/s12888-020-02960-y

Sun, S. F., Goldberg, S. B., Lin, D. H., Qiao, S., \& Operario, D. (2021). Psychiatric Symptoms, Risk, and Protective Factors among University Students in Quarantine during the COVID-19 Pandemic in China. Globalization and Health, 17, Article No. 15.

https://doi.org/10.1186/s12992-021-00663-x

Torous, J., Nicholas, J., Larsen, M. E., Firth, J., \& Christensen, H. (2018). Clinical Review of User Engagement with Mental Health Smartphone Apps: Evidence, Theory and Improvements. Evidence-Based Mental Health, 21, 116-119.

https://doi.org/10.1136/eb-2018-102891

Verger, P., Guagliardo, V., Gilbert, F., Rouillon, F., \& Kovess-Masfety, V. (2010). Psychiatric Disorders in Students in Six French Universities: 12-Month Prevalence, Comorbidity, Impairment and Help-Seeking. Social Psychiatry and Psychiatric Epidemiology, 45, 189-199. https://doi.org/10.1007/s00127-009-0055-Z

Vidourek, R. A., King, K. A., Nabors, L. A., \& Merianos, A. L. (2014). Students' Benefits and Barriers to Mental Health Help-Seeking. Health Psychology and Behavioral Medicine: An Open Access Journal, 2, 1009-1022.

https://doi.org/10.1080/21642850.2014.963586

Wathelet, M., Duhem, S., Vaiva, G., Baubet, T., Habran, E., Veerapa, E. et al. (2020). Factors Associated with Mental Health Disorders among University Students in France Confined during the COVID-19 Pandemic. JAMA Network Open, 3, e2025591.

https://doi.org/10.1001/jamanetworkopen.2020.25591

Xu, Z., Huang, F., Koesters, M., Staiger, T., Becker, T., Thornicroft, G., \& Ruesch, N. (2018). Effectiveness of Interventions to Promote Help-Seeking for Mental Health Problems: Systematic Review and Meta-Analysis. Psychological Medicine, 48, 2658-2667. https://doi.org/10.1017/S0033291718001265 